\title{
CFD ANALYSIS OF LLNL DOWNDRAFT TABLE
}

\author{
Elizabeth U. Finlayson \\ Buvana Jayaraman \\ Astrid R. Kristoffersen* \\ Ashok J. Gadgil
}

\section{Indoor Environment Department, Lawrence Berkeley National Laboratory *Fullbright Visiting Scholar at LBNL from Norwegian Building Research Institute}

\section{$\underline{\text { OBJECTIVES }}$}

This study examines the airflow and contaminant transport in an existing room (89"x77"x98") that houses a downdraft table at LLNL. The facility was designed and built in the 1960's and is currently being considered for redesign. One objective of the redesign is to reduce airflow while maintaining or improving user safety. Because this facility has been used for many years to handle radioactive material it is impractical to conduct extensive experimental tests in it. Therefore, we have performed a Computational Fluid Dynamic (CFD) analysis of the facility. The study examines the current operational condition and some other cases with reduced airflow. Reducing airflow will lead to savings in operating costs (lower fan power consumption), and possible improvements in containment from reduced turbulence. In addition, we examine three design (geometry) changes. These are: (1) increasing the area of the HVAC inlet on the ceiling, (2) adding a $15^{\circ}$ angled ceiling inlet and (3) increasing the area of the slot in the doorway. Of these three geometry modifications, only the larger doorway slot leads to improved predicted containment.

\section{$\underline{A P P R O A C H}$}

\section{$\underline{\text { GEOMETRY }}$}

The facility, shown schematically in Fig. 1, consists of two rooms connected by a doorway. In the first room, the change room, the worker puts on protective clothing. This room provides an entrance to the second room, the downdraft room, which contains the downdraft table located against a wall. This wall has in it a pass-through window directly above the downdraft table. Contaminated packages are brought into the room through this window and then the window is closed shut. As the facility is currently operated, 2600 CFM of air flows through a slot in the 
doorway towards the downdraft table and 1000 CFM of air flows down onto the table from an HVAC inlet in the ceiling of the downdraft room. This airflow exits through the downdraft table, attaining a speed of 670 linear feet per minute at the downdraft tabletop grille. It is expected that this airflow creates significant turbulence in the room and could cause contamination of the worker whose breathing zone is in the wake of the airflow coming from the open door. So, we also investigated a single downward flow to see if it would provide improved containment (i.e. improved safety conditions).

The change room is excluded from the CFD computational domain. When the door is closed the details of the airflow within the change room are assumed to have no effect on the airflow in the downdraft room. The door has a vertical slot of dimension 32 ” 18 ", with its lower edge located at 4 inches from the floor level. A larger slot of dimension $56 " \times 18$ "is also considered in the present study. Air flows through the door slot into the downdraft room, normal to the doorway, and is treated as a boundary condition. The airflow from the HVAC inlet in the ceiling is assumed to be straight down for most of the cases. A simplified model of a worker is included to simulate the effect of flow blockage by the worker. The worker is assumed to be in a protective suit and thermal plume of the worker is neglected (owing to larger than an order of magnitude difference between the plume velocity in still air, and the downdraft room airspeeds). The worker is holding an object representing a contaminated package. The package is held above the downdraft table surface and away from the edge in order to represent standard working conditions.

The geometry of the room was obtained from plans produced using Pro-E software. These files were converted into a hexahedral finite volume mesh for the computations. Figures 2 and 3 show the section planes that will be used to display the results.

The final grid chosen for the study had about 375,000 nodes. The resolution at the boundaries was 0.4 inches, adequate for isothermal room flow that does not simulate boundary layer transfer processes (Gadgil et al, 2003). 


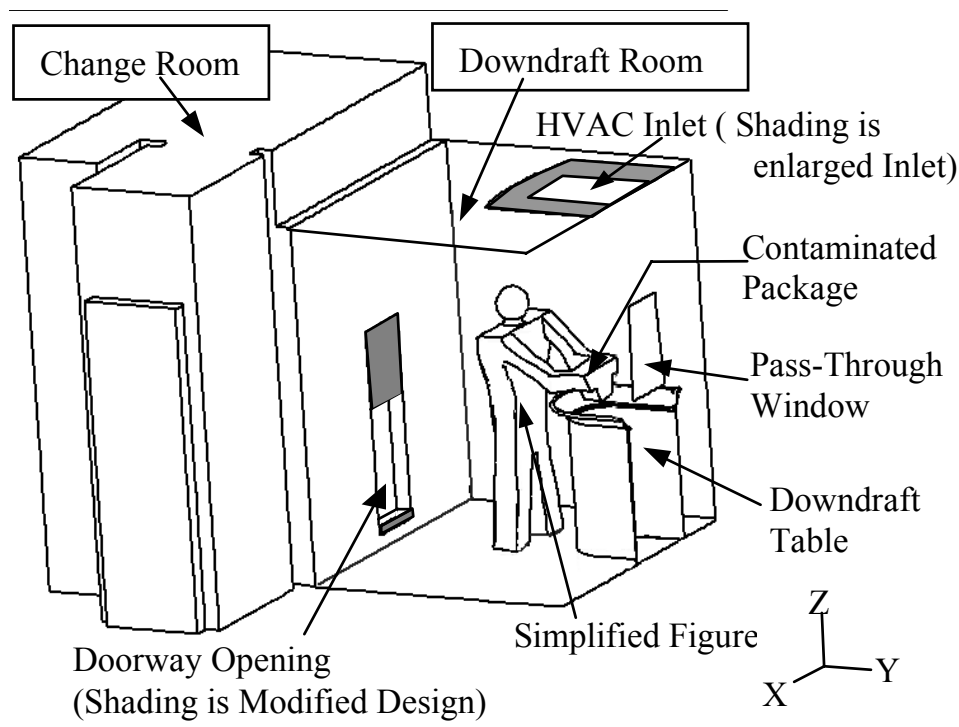

Figure 1: Facility geometry including the change room, to the left, and the downdraft room to the right. The geometry includes the downdraft table, simplified worker figure holding the contaminated package, slot in the doorway, pass-through window, and HVAC air inlet in the ceiling.

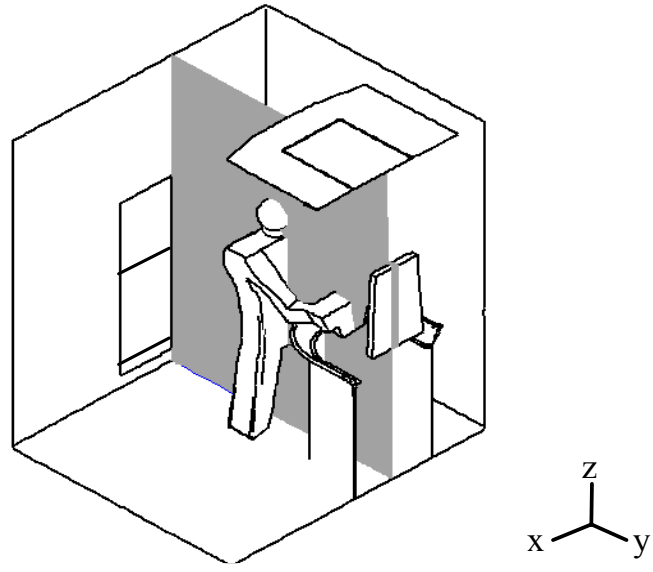

Figure 2: The Y-Z section used for displaying results. The plane passes through the middle of the figure showing the asymmetry of the downdraft table within the room. Center plane of downdraft table is 33" from the left hand side wall and 56" from the right hand side wall. This section illustrates the containment in front of the worker, and around the package. 

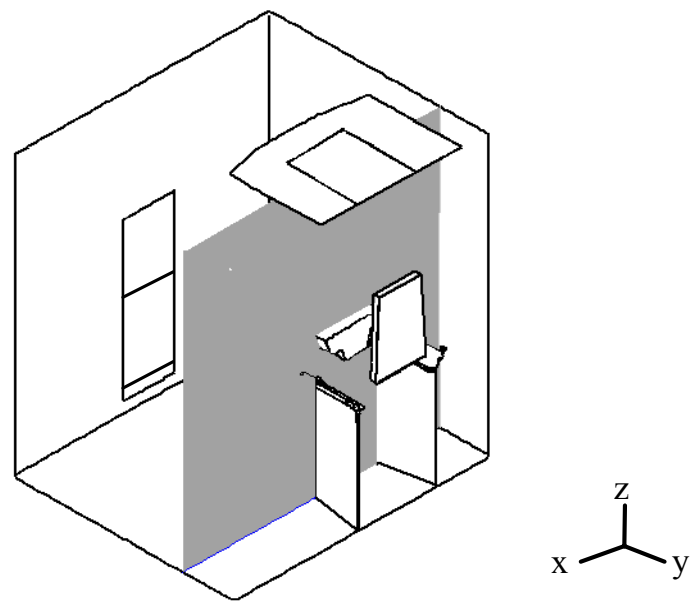

Figure 3. The $X-Z$ section used for displaying results. The plane cuts through the middle of the contaminated package. This view shows how the contamination is spread into the room differently on either side of the table.

\section{COMPUTATIONAL METHOD}

The CFD calculations are performed using the Reynolds Averaged form of the Navier Stokes Equations (RANS). The flow is considered incompressible and isothermal with constant air properties. The standard $\mathrm{k}-\varepsilon$ turbulence model $(\mathrm{Eq} 3,4)$ is used. A finite volume formulation of the following set of equations is solved using the commercial software Star-CD (Adapco, 2001).

$$
\begin{aligned}
& \frac{\partial \mathrm{U}_{\mathrm{j}}}{\partial \mathrm{x}_{\mathrm{j}}}=0 \\
& U_{j} \frac{\partial U_{i}}{\partial x_{j}}=-\frac{1}{\rho} \frac{\partial P}{\partial x_{i}}+\frac{\partial}{\partial x_{j}}\left(v \frac{\partial U_{i}}{\partial x_{j}}\right)+\frac{2}{3} \frac{\partial k}{\partial x_{i}} \\
& \mathrm{U}_{\mathrm{j}} \frac{\partial \mathrm{k}}{\partial \mathrm{x}_{\mathrm{j}}}=\frac{\partial}{\partial \mathrm{x}_{\mathrm{j}}}\left(\mathrm{v} \frac{\partial \mathrm{k}}{\partial \mathrm{x}_{\mathrm{j}}}\right)+v_{\mathrm{turb}}\left(\frac{\partial \mathrm{U}_{\mathrm{i}}}{\partial \mathrm{x}_{\mathrm{j}}}+\frac{\partial \mathrm{U}_{\mathrm{j}}}{\partial \mathrm{x}_{\mathrm{i}}}\right) \frac{\partial \mathrm{U}_{\mathrm{i}}}{\partial \mathrm{x}_{\mathrm{j}}}-\varepsilon \\
& U_{j} \frac{\partial \varepsilon}{\partial x_{j}}=\frac{\partial}{\partial x_{j}}\left(\frac{\mathrm{v}}{1.22} \frac{\partial \varepsilon}{\partial x_{j}}\right)+\frac{\varepsilon}{k}\left[\mathrm{v}_{t u r b} 1.44\left(\frac{\partial U_{i}}{\partial x_{j}}+\frac{\partial U_{j}}{\partial x_{i}}\right) \frac{\partial U_{i}}{\partial x_{j}}\right]-1.92 \frac{\varepsilon^{2}}{k}
\end{aligned}
$$

$$
\mathrm{U}_{\mathrm{j}} \frac{\partial M}{\partial x_{j}}=\frac{\partial}{\partial x_{j}}\left(D_{\text {molec }}+\frac{v_{\text {turb }}}{\sigma_{m}}\right) \frac{\partial M}{\partial x_{j}}
$$

where: $\mathrm{P}$ is the pressure; $\rho$ is the density; $\mathrm{U}_{\mathrm{i}}$ are the mean velocity components; $\mathrm{x}_{\mathrm{i}}$ are rectilinear orthogonal coordinates; $\mathrm{k}$ is the turbulent kinetic energy; $\varepsilon$ is the dissipation rate of $\mathrm{k}$; $\mathrm{M}$ is the tracer concentration. And $v=v_{\text {turb }}+v_{\text {molec }}$ where $v_{\text {molec }}$ is the molecular kinematic viscosity and $v_{\text {turb }}$ is the turbulent kinematic viscosity: $v_{\text {turb }}=0.09 \mathrm{k}^{2} \varepsilon^{-1}$. 
$\mathrm{D}_{\text {molec }}$ is the molecular diffusivity of air in air and $\sigma_{\mathrm{m}}$ is the turbulent Schmidt number, assigned a value of 0.6 based on Finlayson et al (2003).

Equations 1-4 are solved to obtain a steady state velocity field in the downdraft room using the SIMPLE (Patankar, 1980) method. The differencing employs a second order scheme based on a Godunov method modified for incompressible flow (Asproulis, 1994). The advantage of this scheme is that it suppresses numerical diffusion without causing instability. The convergence criterion used for the velocity field is that the normalized sum of the residuals is less than $1.0 \mathrm{e}-3$ for each of the variables.

Containment is studied for a given velocity field by first checking the flow paths of massless particles, and then, in more detail, checking the predicted concentration of tracer gas. Both the massless particles and the tracer gas are released from the package and the two locations where "worst-case" containment is expected: from the rim of the downdraft table and the perimeter of the (closed) window in the wall behind the downdraft table. See Figure 4. Tracks of airborne massless particles give a good indication of whether contamination will be contained with respect to the mean flow. This is a reasonable minimum criterion to assure containment.

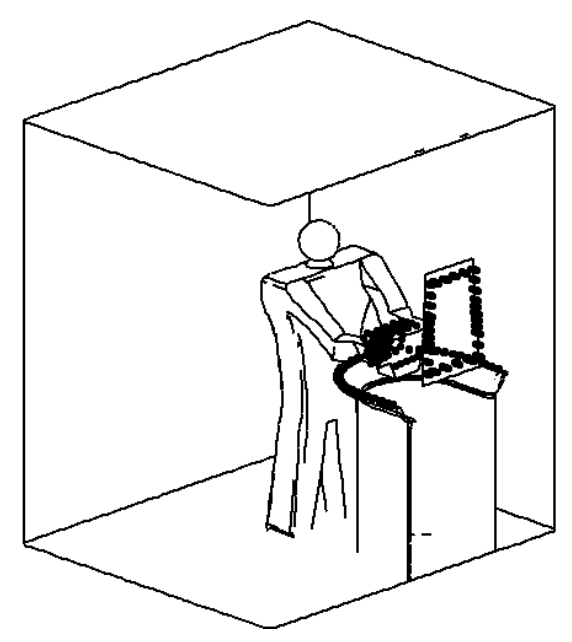

Figure 4. Locations of release of massless particles used to determine containment based on mean velocity criterion are shown as black dots.

DISCUSSION OF EXISTING CASE 
$10 / 08 / 03$

LBNL-53883

As a first step we explored the containment capability of the existing configuration. Figure 5 shows the particles fully contained using the current configuration with airflow of $1000 \mathrm{CFM}$ downward and 2600 CFM through the door.

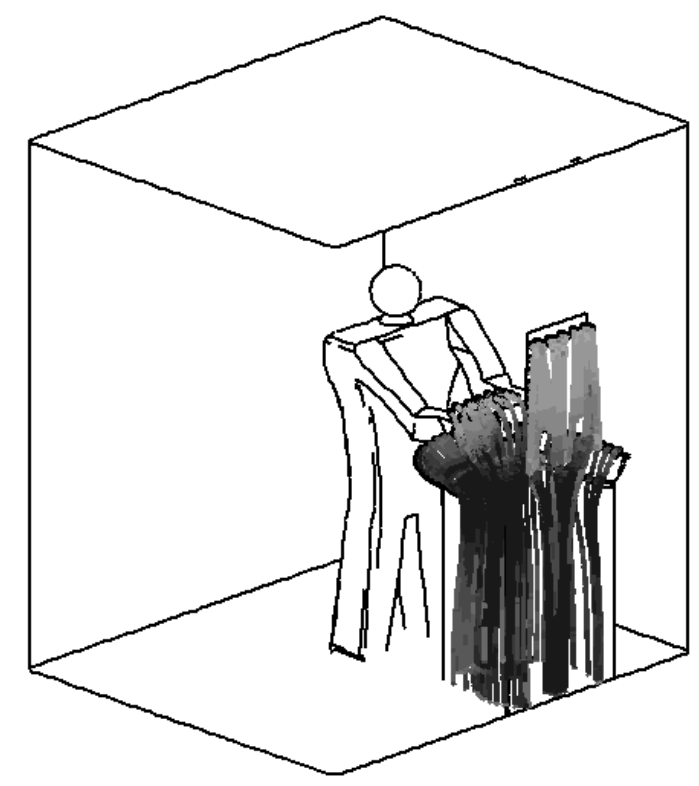

Figure 5. All particles released are contained within the downdraft table for flow supplied through the opening in the doorway at 2600 CFM and the ceiling at 1000 CFM.

Particle tracks can only show the effects of the mean velocity. The additional mixing in the room from turbulent fluctuations can cause reduced containment and increased contamination. One way of examining this effect would be to perform a Large Eddy Simulation (LES) and actually calculate the turbulent eddies. This approach would have increased the computational and human effort for analysis by a factor of more than 10. On the other hand, our research (Finlayson et al., 2003) shows that a RANS model with a second order differencing scheme that suppresses numerical diffusion can provide acceptable (i.e., within a factor of two compared to experimental measurements) detailed predictions for pollutant dispersion. To evaluate the additional diffusion caused by turbulence, we release a passive scalar representing a neutrally-buoyant tracer gas at the rim of the downdraft tabletop and the perimeter of the pass through window. Passive trace gas has very high diffusivity, much larger than that of particulate contaminants, and represents a maximum criterion for containment. Since there are 375,000 nodes, and at end of calculations the sum of the residuals is $1.0 \mathrm{e}-3$, full containment is considered attained below normalized concentration of $1.0 \mathrm{e}-8$ (normalization is with respect to tracer gas concentration at release locations). Lower values than this are suspect owing to numerical errors from non-zero residuals. 

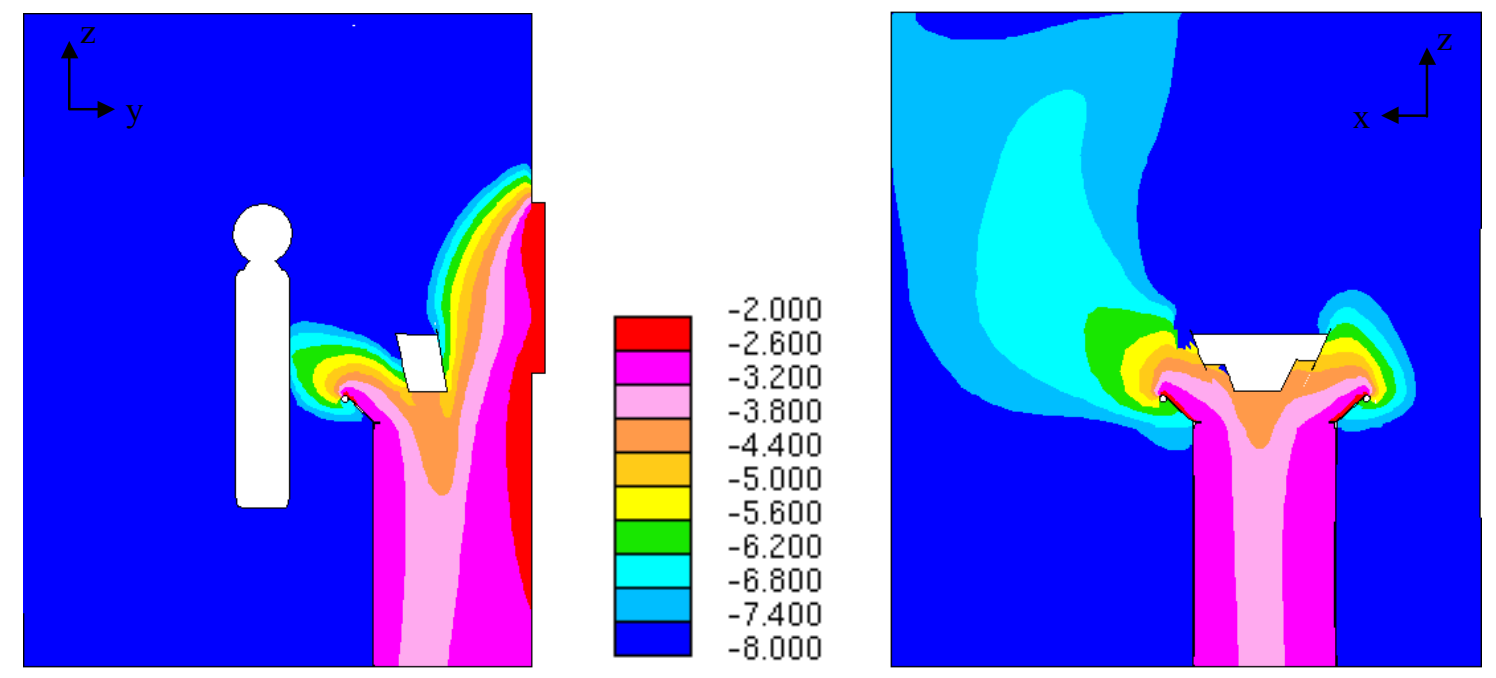

Figure 6. Concentration contours (log of normalized concentration) for existing configuration.

Ceiling flow 1000 CFM, door flow 2600 CFM (Case A in Table 2 below) .

Examination of the simulated tracer gas concentration throughout the downdraft room gives an indication of how contamination could be spread due to turbulent effects. Figure 6 shows the concentration contours for the existing configuration. In the $y-z$ view, the contaminant has escaped from the downdraft table and touches the worker's chest. In the $\mathrm{x}-\mathrm{z}$ view, reasonable containment is observed on the right half of the figure, but on the left side the contamination is spread by the recirculating flow.

\section{ALTERNATE CONFIGURATIONS}

We considered several modifications to the existing room operation and geometry. The description of geometry changes is shown in Table 1 . The description of the cases including HVAC conditions is summarized in Table 2.

Table 1: Definitions of inlet geometries

\begin{tabular}{|l|l|l|}
\hline Inlet type & Description & Area in square inches \\
\hline HVAC Air Inlet & Existing & 500 \\
\hline
\end{tabular}




\begin{tabular}{|l|l|l|}
\hline & Large & 1658 \\
\hline Opening in back doorway & Existing & 576 \\
\hline & Modified & 1009 \\
\hline
\end{tabular}

Table 2: Summary of cases investigated

\begin{tabular}{|l|l|l|l|l|l|}
\hline Case & Ceiling inlet size & Door Slot size & $\begin{array}{l}\text { Total } \\
\text { Flow } \\
\text { (CFM) }\end{array}$ & $\begin{array}{l}\text { Door Flow } \\
\text { (CFM) }\end{array}$ & $\begin{array}{l}\text { Ceiling Flow } \\
\text { (CFM) }\end{array}$ \\
\hline A & Existing & Existing & 3600 & 2600 & 1000 \\
\hline B & Existing & zero & 800 & & 800 \\
\hline C & Existing & zero & 1600 & & 1600 \\
\hline D & Existing & Existing & 1200 & 800 & 400 \\
\hline E & Existing & Existing & 1600 & 800 & 800 \\
\hline F & Existing & Existing & 2000 & 1200 & 800 \\
\hline G & Existing & Existing & 2200 & 1200 & 1000 \\
\hline H & Existing & Existing & 2400 & 1600 & 800 \\
\hline I & Existing & Existing & 2200 & 1600 & 600 \\
\hline J & Existing & Tall & 1200 & 800 & 400 \\
\hline K & Existing & Tall & 2400 & 1600 & 800 \\
\hline L & Large & zero & 800 & & 800 \\
\hline M & $15^{\circ}$ Air Inlet & zero & 800 & & 800 \\
\hline
\end{tabular}

Case A is the existing configuration with air supply through the door and through the ceiling inlet for a total flow of 3600 CFM. Results from Case A are shown in Figure 6. Cases B and C are simulated with purely downward flows (i.e. with the door slot closed) using the existing ceiling inlet geometry with flow rates of 800 and 1600 CFM. Figure 7 shows the massless particle trajectory for Case B. The particles released from the locations defined in Figure 4 were not contained by this flow. Particles released from the downdraft table rim on the left side of the table (facing the worker) are dispersed into the room. These particles are entrained in the large recirculation loop in this part of the room. The nearness of the wall to the right side of the table suppresses this loop and the particles on that side of the table are contained. 


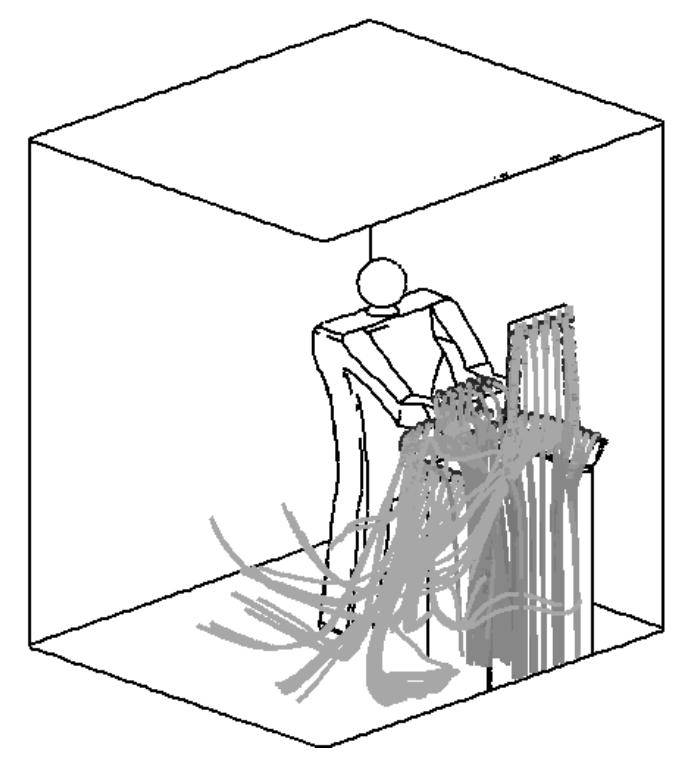

Figure 7. For flow supply through the ceiling alone, we find only partially successful containment.

A flow rate of $1080 \mathrm{CFM}$ is necessary to provide the recommended velocity of $200 \mathrm{ft} / \mathrm{min}$ at the face of the downdraft table (ACGIH, 1995). Case B, with an airflow of only 800 CFM from the ceiling diffuser, and door slot closed, does not meet this criterion. The airflow in Case $\mathrm{C}$ does meet this criterion. However, we observed that the increased airflow in Case $\mathrm{C}$ does not solve the containment problem.

Cases $\mathrm{L}$ and $\mathrm{M}$ were simulated to try to improve the containment using flow only from the ceiling. Case L used an enlarged opening with improved symmetry with respect to the downdraft table. This configuration creates a flow pattern at the perimeter of the downdraft tabletop that is directed inwards towards the table rather than outwards towards the room. Case $M$ was an attempt to effectively increase the size of the ceiling inlet directing half of the flow out at 15 degrees from the ceiling. The remaining half of the flow in the center of the inlet was directed straight down as before. Neither of these cases created the flow necessary to contain even the massless particles (containment of the tracer gas would be even poorer). Since none of the cases with pure downward flow can satisfactorily contain the massless particles we explored cases that include the flow through the slot in the door. These simulations are similar to the existing setup, but with a reduced flow from the ceiling and the door slot. The majority of the cases, (D-I), use the existing size of the door slot. Cases J and $\mathrm{K}$ explore improvements to containment provided by a larger door slot. 


\section{$\underline{\text { RESULTS AND DISCUSSIONS }}$}

The cases described in Table 2 are a subset of the cases that were simulated with CFD in the course of this study. From the examination of all the cases studied, it was found that the flow through the opening in the doorway must be greater than or equal to the ceiling inlet flow to obtain containment. In addition, we set a minimum total acceptable flow as 1200 CFM (so that the average air speed at the downdraft table face exceeds the recommended value of $200 \mathrm{ft}$. per minute (ACGIH, 1995)).

Figure 8 shows the concentration contours for case D, which uses the minimum total acceptable flow of 1200 CFM. The normalized concentration contours are presented in the log scale. All concentration plots are presented using the scale from -8 to -2 . Note that the neutrally-buoyant tracer gas is released at the rim of the downdraft table and at the perimeter of the pass through window. Hence higher tracer concentration can be expected around these locations.
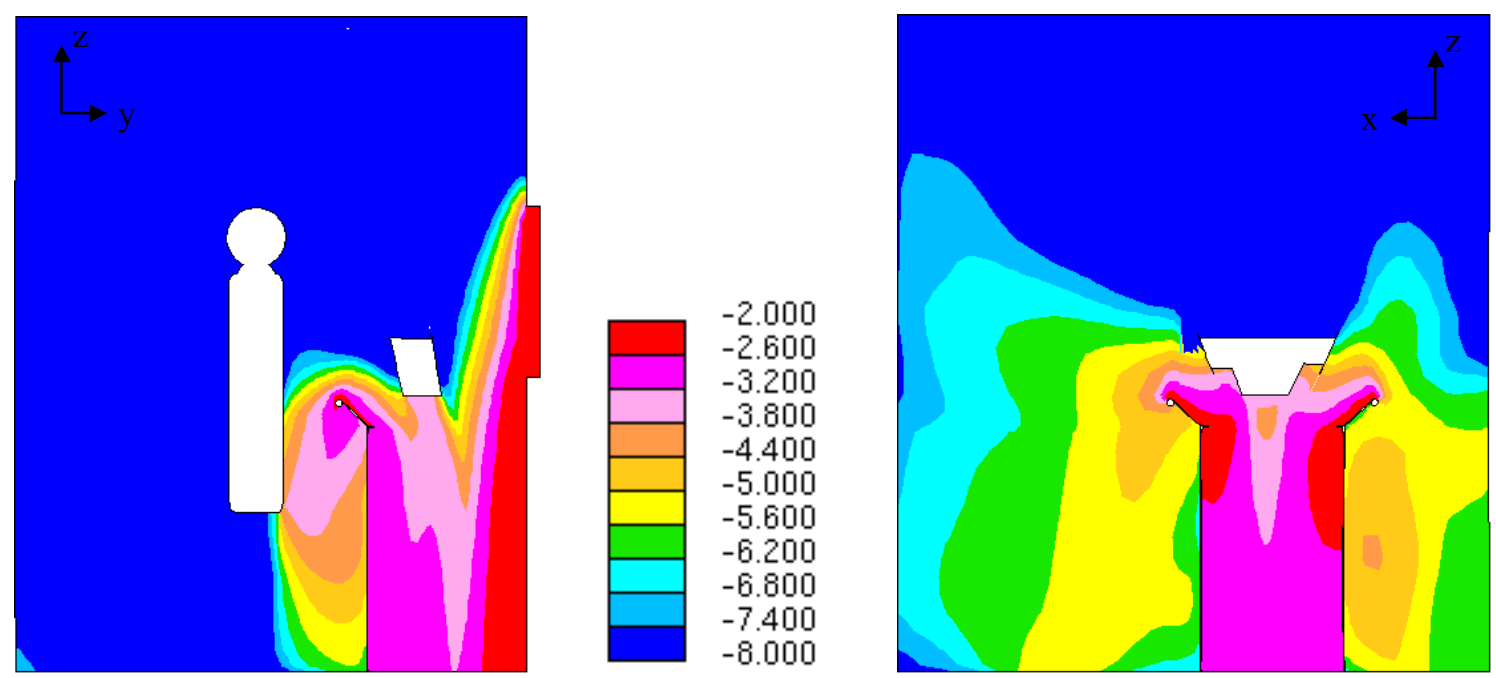

Figure 8. Concentration contours for Case D, ceiling flow 400 CFM, door flow 800 CFM.

Figure 9 shows the concentration contours for Case E, which shows that increasing the ceiling inlet flow while keeping the flow through the door slot equal to that in Case $\mathrm{D}$, improves the containment of the contaminant. 

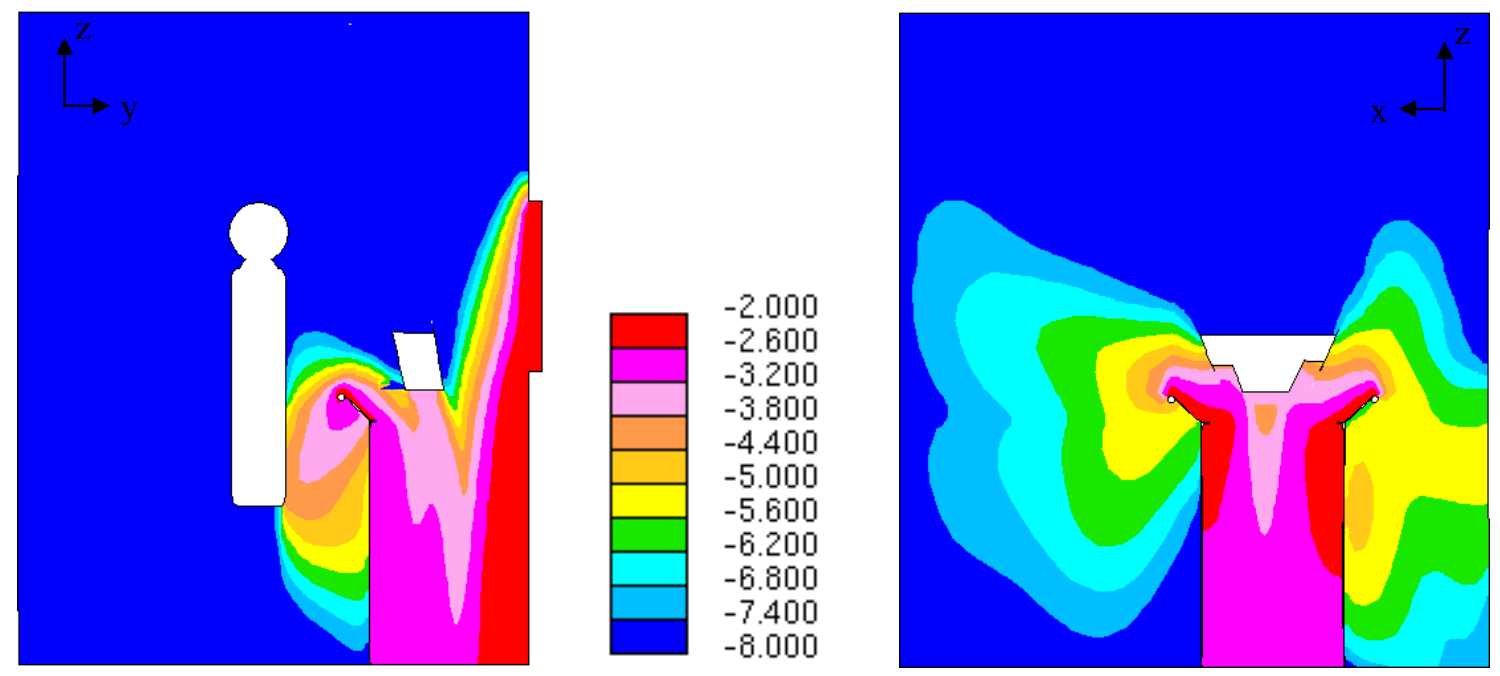

Figure 9. Concentration contours for Case E, ceiling flow 800 CFM, door flow 800 CFM.

Case $\mathrm{F}$ is carried out by keeping the same ceiling inlet flow as in Case $\mathrm{E}$ and increasing the flow through the door slot to $1200 \mathrm{CFM}$. Figure 10 shows the concentration contours for Case F. Comparison between Figures 9 and 10 shows that, the increased flow through the door slot significantly improves the containment.
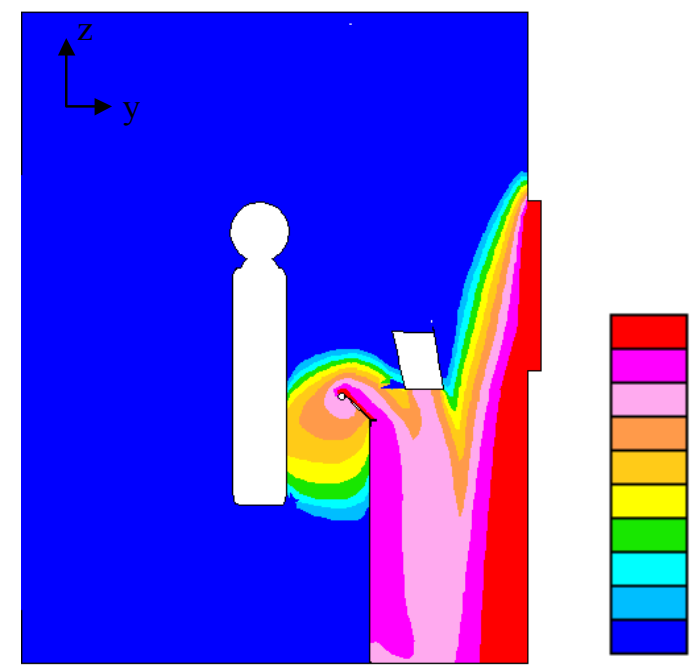

$-2.000$

$-2.600$

$-3.200$

$-3.800$

$-4.400$

$-5.000$

$-5.600$

$-6.200$

$-6.800$

$-7.400$

$-8.000$

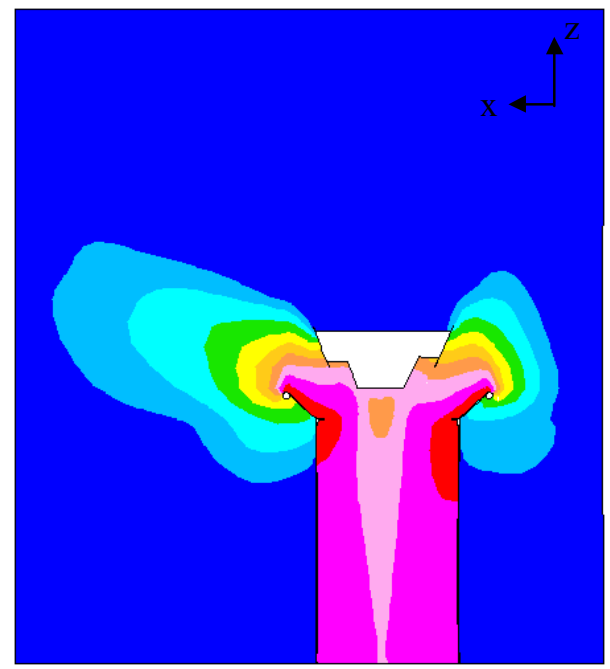

Figure 10. Concentration contours for Case F, ceiling flow 800 CFM, door flow 1200 CFM. 
$10 / 08 / 03$

LBNL-53883

Figure 11 shows the concentration contours for Case G. In this case the ceiling inlet flow is increased to $1000 \mathrm{CFM}$ and the flow through the door slot is fixed at $1200 \mathrm{CFM}$ as in the previous case. The increase in the downflow results in degradation of the containment.
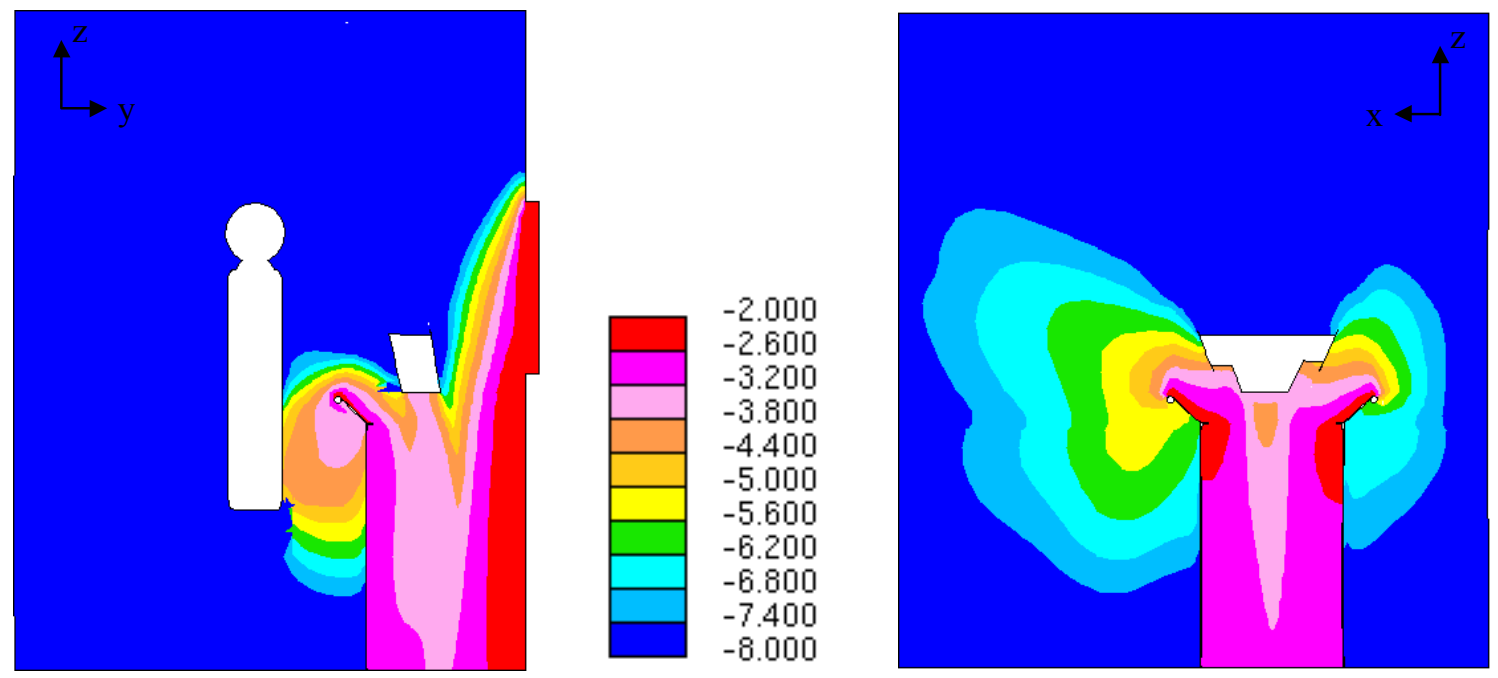

Figure 11. Concentration contours for Case G, ceiling flow 1000 CFM, door flow 1200 CFM.

Based on cases $\mathrm{F}$ and $\mathrm{G}$, we recommend a maximum airflow of 800 CFM through the ceiling inlet. However, since the existing configuration delivers 1000 CFM from the ceiling and the containment degradation is small, it might not warrant a design modification.

Figure 12 shows the concentration contours for Case H, with 1600 CFM flow through the door slot and 800 CFM flow through the ceiling inlet. This higher flow through the door slot shows a further improved containment, even better than Case F (Figure 10). We also looked at a case with 1600 CFM through the door slot and 1000 CFM ceiling inlet flow (not included in Table 2), and found a degradation similar to that seen between Cases F and G. We explored containment improvements by increasing the flow rate through the door at $200 \mathrm{CFM}$ increments from 1600 to 2600 CFM and found that the airflow of 1600 CFM through the slot in the doorway provided the best containment. 

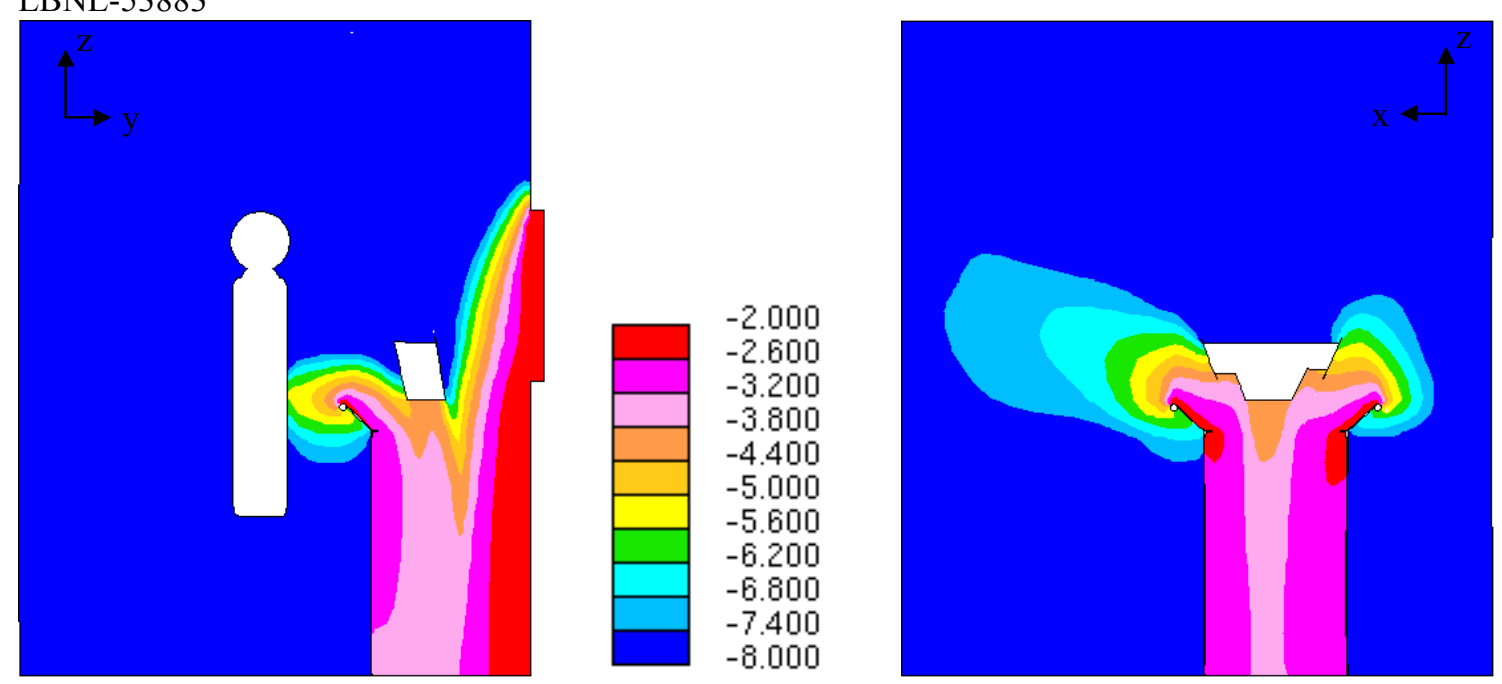

Figure 12. Concentration contours for Case H, ceiling flow 800 CFM, door flow 1600 CFM.

At door slot flow of 1600 CFM, we again explored the possibility of reducing the ceiling flow. Two more cases with a flow rate of 600 and 400 CFM through the ceiling inlet and a fixed 1600 CFM flow through the door slot were carried out. Degradation of the containment was observed with ceiling inlet flow rates less than 800 CFM. Thus, we concluded that Case H with 1600 CFM flow through the door slot and 800 CFM flow through the ceiling inlet results in the best containment with the existing geometry.

The concentration contours shown in Figure 12 are predictions for a tracer-gas release at the rim of the downdraft table (at velocity $0.02 \mathrm{ft} / \mathrm{min}$ away from the rim). Since the tracer gas instantaneously responds to the turbulent fluctuations, its release provides an estimate of containment of species with high diffusivity. Particles have lower diffusivity than tracer gas, so, particles released at the same locations and with the same velocity, will diffuse less, follow the streamlines more closely, and thus be better contained than tracer gas.

Since the turbulent intensity is highest in the room at the rim of the table, it is not surprising that tracer gas released at the rim can not be fully contained. The high turbulent intensity at the rim leads to high turbulent diffusivity, which leads to instantaneous (though small) diffusive escape of some of the tracer gas from the rim into the room. To investigate this matter further, we conducted several simulations, in which tracer gas was released in concentric rings at various distances from the center of the table to the table rim. These simulation results (not shown here) 
$10 / 08 / 03$

LBNL-53883

indicate full containment of tracer gas for any release more than 4 inches inside the rim of the table. Thus, we recommend that the packages be opened only in this "containment zone."

However, particles can be released with a velocity larger than $0.02 \mathrm{ft} / \mathrm{min}$, owing to small mechanical energy being imparted to them. In that case, the particles will initiate their travel with some momentum, and may not follow the streamlines. We demonstrate below that this is not a cause for concern.

Mechanically generated powder constituents are always larger than about 10 microns. For a given launch velocity, larger particles travel farther before coming to momentum equilibrium with the surrounding air. The time for reaching equilibrium is called the relaxation time. Consider a 100 micron particle released from the rim of the containment zone of the downdraft table, towards the rim. (Recall that the containment zone for the downdraft table is the area excluding a 4-inch wide annular region bordering on the rim of the table.) The relaxation time for a 100 micron particle is $3.1 \times 10^{-2}$ seconds (Hinds, 1999). A launch velocity of more than $1200 \mathrm{ft} / \mathrm{min}$ would be required for the particle to reach the rim. For a 10 micron particle the velocity would be two orders of magnitude higher. Since the downdraft table is not used for explosive releases, we do not anticipate particles leaving the package at velocities high enough to reach the rim. Thus, the containment zone is valid for full containment of non-energetic release of particles and gases.

\section{DESIGN MODIFICATION}

After determining the best flow conditions for the existing room, we explored the effect of increasing the size of the slot in the doorway (Cases J and K). Figure 13 shows the concentration contours for Case J. Comparing Fig. 13 with Fig. 12 (for Case H), we see a somewhat degraded containment in the y-z plane. The contamination reaches the worker higher up on the body nearer to the breathing zone. In the $\mathrm{x}-\mathrm{z}$ plane, we see significantly decreased contaminant spread on the left side of the table, because the low flow through the door slot decreases the strength of the recirculation region. 

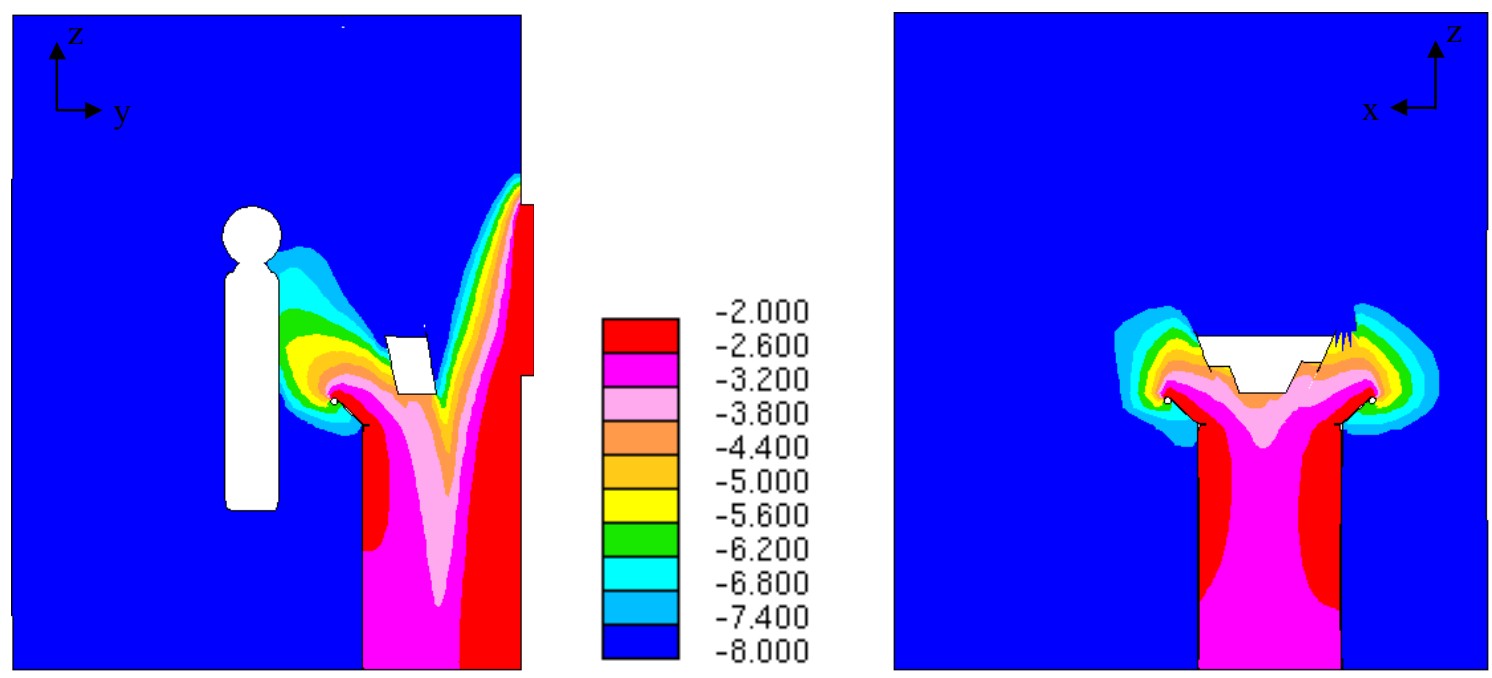

Figure 13. Concentration contours for Case J, ceiling flow 400 CFM, door flow 800 CFM.

Figure 14 shows the tracer gas concentrations for Case $\mathrm{K}$ with the taller opening in the doorway. These results show that containment is not significantly improved with increased flow rate.
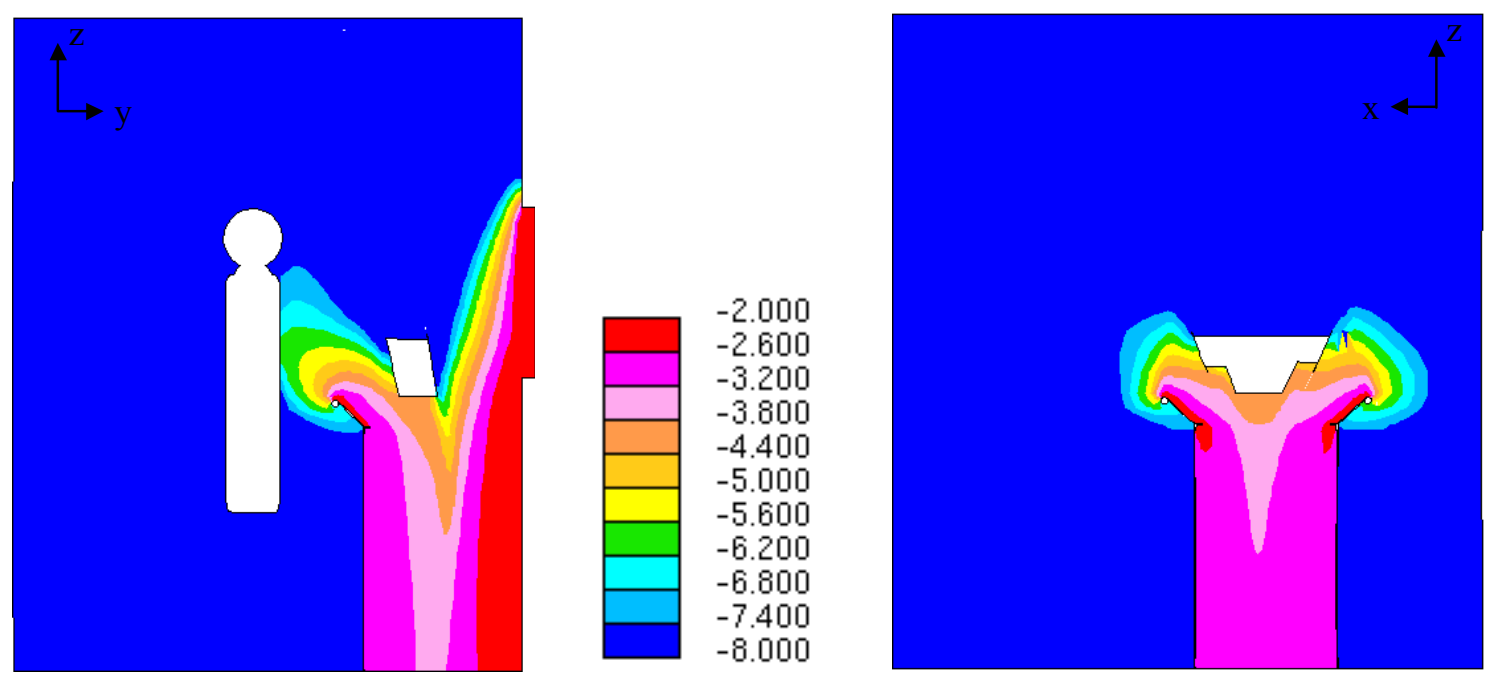

Figure 14. Concentration contours for Case K, ceiling flow 800 CFM, door flow 1600 CFM.

The goal in downdraft design is to have low turbulence flow conditions, because containment can be defeated by large turbulent fluctuations. Figure 15 compares the turbulent kinetic energy of Cases A and H. It can be seen that the turbulent kinetic energy is significantly lower in Case $\mathrm{H}$ and better containment may be achieved. 


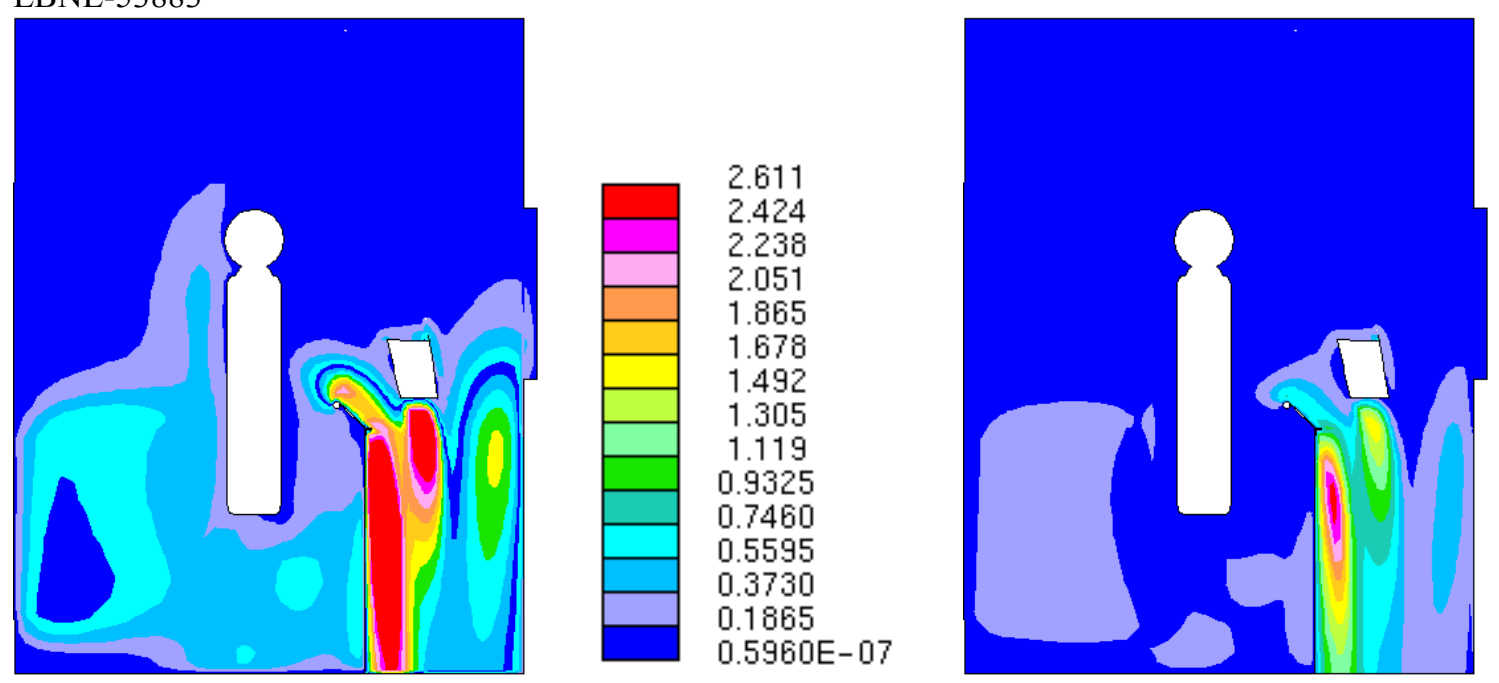

Figure 15: Turbulent kinetic energy contours for Case A (left) and $H$ (right)

\section{CONCLUSIONS}

Containment of massless particles is a minimum condition to indicate adequate containment in the downdraft table. Containment of a tracer gas shows adequate containment at the upper limit of diffusivity, in absence of energetic particle releases. Analysis of energetic particle releases must be carried out to ensure that tracer gas containment still applies to such particle releases under expected realistic initial velocities. Full containment of tracer gas released from the table is assumed for normalized concentrations less than $10^{-8}$. This assumption should hold for typical particles with a low velocity release from the package.

We found that airflow through the door slot is essential to ensure good containment.

For a release within the downdraft table to be contained by the mean flow, the flow rate through the door slot must be equal to or greater than that through the ceiling inlet. This is true for both sizes of the door slot.

A taller door does not improve containment.

Existing flow conditions (Case A, Figure 6) are not optimal. Better containment and improved protection of worker's breathing zone could be achieved if the flow through the door was reduced from $2600 \mathrm{CFM}$ to $1600 \mathrm{CFM}$ (Case H, Figure 12).

For the existing geometry, the optimal flow is 1600 CFM through the door slot, and 800 CFM through the ceiling inlet. We believe that the range of acceptable operating conditions (i.e., least exposure of worker to normalized concentrations higher than $10^{-8}$ ), centered on these flow values, is +/- 200 CFM. 
$\underline{\text { ACKNOWLEDGEMENTS }}$

This work was supported by Lawrence Livermore National Laboratory and performed for the U.S. Department of Energy under Contract No. DE-AC03-76SF00098.

\section{REFERENCES}

ACGIH, 1995. Industrial Ventilation A Manual of Recommended Practice $22^{\text {nd }}$ Edition American Conference of Governmental Industrial Hygenists.1995

Adapco, 2001. Star-CD Version 3.15 Methodology, Adapco 2001

Asproulis, 1994. Asproulis, P. N., High Resolution Numerical Predictions of Hypersonic Flows on Unstructured Meshes, Ph.D. Dissertation, Imperial College, Dept. of Aeronautics, London, England

Finlayson et al., 2003. Finlayson, E. U., Gadgil, A. J., Thatcher, T. L. and Sextro, R. G., Pollutant Dispersion in A Large Indoor Space: Computational Fluid Dynamics (CFD) Predictions and Comparison with A Scale Model Experiment for Isothermal Flow, Lawrence Berkeley National Laboratory Report LBNL-50105, April 2003. (Accepted for publication in Indoor Air)

Gadgil et al., 2003. Gadgil, A. G., Lobscheid, C., Abadie, M. O. and Finlayson, E. U., Indoor Pollutant Mixing Time in an Isothermal Closed Room: An Investigation using CFD, Lawrence Berkeley National Laboratory Report LBNL-51413. (Accepted for publication in Atmospheric Environment)

Hinds, 1999. Hinds, W. C., Aerosol Technology, 2 $2^{\text {nd }}$ Edition, John Wiley 1999

Patankar, 1980. Patankar, S. V., Numerical Heat Transfer and Fluid Flow, Hemisphere, Washington, D.C. 